\title{
Association of Dairy Intake with Hypertension and Metabolic Syndrome in a Community-Based Brazilian Adults
}

\section{Tatiana Cristina Figueira Polo ${ }^{1}$, Silvia Justina Papini ${ }^{2}$, Katia Portero Sloan ${ }^{3}$, Patricia Baston Frenhani and Roberto Carlos Burini ${ }^{5}$}

${ }^{1}$ Graduate Program of Pathology, UNESP Medical School, Botucatu, Brazil

${ }^{2}$ Department of Nursing, UNESP Medical School, Botucatu, Brazil

${ }^{3}$ Texas Institute for Kidney and Endocrine Disorders, Lufkin, TX, USA

${ }^{4}$ School of Nutrition, Centre for Life Sciences Courses (CCV) - PUC-Campinas, Brazil

${ }^{5}$ Department Public Health, UNESP Medical School, Botucatu, Brazil

*Corresponding author: Katia Portero Sloan, Texas Institute for Kidney and Endocrine Disorders, 10 Medical Center Blvd, Ste A Lufkin, TX 75904, USA, E-mail: kaportero@gmail.com

\begin{abstract}
Background: Results of epidemiological studies that have evaluated the relationship between dairy food consumption and risk of metabolic syndrome are not consistent and sometimes controversial.

Objective: We performed the present study to identify the association of dairy intake and the metabolic syndrome and its individual components (abdominal obesity, low HDLcholesterol, hypertriglyceridemia, hyperglycemia and high blood pressure).

Methods: This study included 763 individuals clinically selected for the lifestyle modification program "Move for health" and fulfilling the inclusion criteria of having data of socioeconomic, demographic, physical activity and dietary assessments, as well as the anthropometric, clinical and biochemical assessments for the metabolic syndrome diagnosis (National Cholesterol Educational Program Treatment Panel III). A 24-h dietary recall was used to estimate the dietary intake and 3 daily servings of dairy were considered as adequate. Statistical analysis was performed using the SAS 9.3 software, t-student, ANOVA, Tukey and logistic regression analysis, adopting the significance level of $p<$ 0.05 .
\end{abstract}

Results: Among the individuals of our cohort, the majority was female, with low family income, poor diet, and abdominal obesity. The lower decile of dairy intake was associated with lower income, lower healthy score index, lower intake of total energy, lower intake of saturated fatty acids, and lower intake of calcium. Lower dairy intake was not associated with the presence of metabolic syndrome and rather, with hypertension.

Conclusion: This study found an inverse association of dairy intake and presence of hypertension, which may support the potential benefit of dairy consumption, as part of a balanced diet and a healthy lifestyle, to prevent the development or delay the onset hypertension in this population.

\section{Keywords}

Dairy, Hypertension, Metabolic syndrome, Obesity

\section{Introduction}

Throughout history, food systems and thus human diets have been and are shaped by climate, terrain, seasons, location, culture, and technology. They can be grouped into three broad types: gather-hunter, peasant-agriculture and urban-industrial [1]. Medical and anthropologic studies have shown that hunter-gatherer societies are largely free of chronic diseases of Western civilization, and this has been attributed partly to their diets [2]. The gather-hunter exhibited a diet with great variety of foods, rich in micronutrients, usually high in animal sources from insect to large animal, high in protein, moderate amounts of fat and starchy foods, 
high in dietary fiber and low in sugar (mostly from fruits and honey) [3]. Hence, the nutritional patterns of the Paleolithic era differed considerably from the current standards in which the food was virtually devoid of cereals, newborns were fed breast milk, but children and adults never touched milk products, and heating was probably the only significant food-processing procedure [4]. Hominins, like all mammals, would have consumed the milk of their own species during the suckling period. However, after weaning, the consumption of milk and milk products of other mammals would have been nearly impossible before the domestication of livestock because of the inherent difficulties in capturing and milking wild mammals [5]. The dietary characteristic of the modern man is its low intake of dairy products, motivated by either socioeconomic, knowledge, or even cultural reasons [6].

Several authors have argued that a discordance between our contemporary diets and the paleolithic-type diets to which evolutionary forces adapted our core metabolism and physiology over a period of millions of years of hominin evolution contributes in a major or critical way to the pathogenesis of the so-called diseases of civilization: atherosclerotic cardiovascular disease and its sequelae, insulin resistance and type 2 diabetes, metabolic syndrome (MetS), age-related sarcopenia and osteoporosis, hypertension and its sequelae, some types of cancers and many others [7]. Among these diseases, MetS is recognized as a pervasive condition and evidence indicates that individuals are approximately twice as likely to develop cardiovascular diseases (CVD) and between 3.5 to 5 times more likely to develop Type 2 diabetes mellitus (T2DM) leading to premature mortality [8]. There are environmental/behavioral risk factors linked to the development of MetS in which the predominants are cigarette smoking, obesogenic-atherogenic diets, and physical inactivity [8].

Dairy represents a group of foods that provide proteins of high biological value, vitamins and minerals and, bioactive peptides [9]. Dairy consumption has shown a beneficial effect on risk factors contributing to the metabolic syndrome, including dyslipidemia, insulin resistance, hypertension and abdominal obesity, which together increase the risk of diabetes and cardiovascular diseases [10-13].

Epidemiological studies have evaluated the relationship between dairy food consumption and risk of the MetS. Some studies reported an inverse association $[14,15]$, but others showed no association [16,17]. A recent systematic review and a meta-analysis of observational studies showed the dose-response relationship between specific types of dairy foods and the risk of the metabolic syndrome and its components. Specifically, this meta-analysis showed that consumption of milk and yogurt as well as total dairy food were inversely related to risk of the MetS and its components [18]. There- fore, we performed the present study to identify the association of dairy intake and the metabolic syndrome and its individual components (abdominal obesity, low HDL-cholesterol, hypertriglyceridemia, hyperglycemia and high blood pressure) in a cohort of a community-based adults enrolled in a lifestyle changing program.

\section{Methods}

Cross-sectional analysis of baseline data from 763 individuals who joined a lifestyle changing program (LISC) between the years of 2006 and 2016. This lifestyle program has been described elsewhere [19] and the inclusion criteria includes participants over the age of 35 , of both genders, with at least one of the metabolic syndrome components and/or comorbidities, and without metabolic or motor disabilities that would limit physical exercise.

\section{Demographic data and socioeconomic status}

Participants were classified by gender, range of age ( $<$ and $\geq 60$ years), family income (measured in monthly minimal income (MI), $1 \mathrm{MI}=\mathrm{U} \$ 250.00$ ) and education (years of school) Education was classified in middle school ( $<5$ years of school) and High School or College $(>5$ years of school).

\section{Biochemical analyses}

For biochemical analyses, the individuals were submitted to blood sample collections after nocturnal fasting (8 a12 hours) by standard venipuncture. Glucose, triglycerides (TG) and high-density lipoprotein cholesterol (HDL-c) concentrations were quantified in serum by the dry chemistry method.

\section{Anthropometric assessment}

Weight and height were measured with a Filizola ${ }^{\circledR}$ electronic scale (capacity and precision in grams), and a stadiometer (precision in millimeters). Waist circumference was measured halfway between the lower rib region and the iliac crest in the recumbent position after a normal exhale by a nonextensible and non-elastic millimeter-graded measuring tape. Body Mass Index [2022] and waist circumference (cm) [23] were assessed according to the literature.

\section{MetS diagnosis}

The individuals were diagnosed as having metabolic syndrome according to the National Cholesterol Education Program Adult treatment Panel III (NCEP-ATP III) [24]. The five components used were plasma concentrations of triglycerides, HDL-c and fasting glucose, arterial hypertension and abdominal circumference. MetS was diagnosed when three or more of these components were altered.

\section{Dietary intake assessment}

The $24 \mathrm{~h}$ dietary recall was used to assess food in- 
take. Dietary data obtained in homemade measurements were converted into grams and milliliters to permit chemical analysis of food intake. The centesimal composition of foods present in the records was processed in the Food and Nutrition Database NutWin, version 1.5, and the principal nutrients of interest were energy (kcal), protein (\%), fat (\%) (saturated fatty acids, monounsaturated fatty acids and polyunsaturated fatty acids), carbohydrates (\%), calcium (mg), sodium (mg) and potassium (mg) (presented as sodium-to-potassium ratio). The results of the dietary data were evaluated by Health Eating Index (HEI) score adapted for the Brazilian population $[25,26]$. The three daily servings of dairy was used as recommended daily intake [27].

\section{Statistical analysis}

Statistical analysis was performed using the SAS 9.3 software, t-student, ANOVA, Tukey and logistic regression analysis, adopting the significance level of $p<0.05$. Initially, a descriptive analysis was performed with frequency and percentage for categorical variables and average and standard deviation for continuous variable. Then, the variables were compared to presence or absence of metabolic syndrome. Test-t was used for symmetric variables and gama distribution for asymmetric variables. ANOVA followed by Tukey test (for symmetric variables) and ANOVA followed by gama (for asymmetric variables) were performed to compare dairy intake in percentiles to the components of metabolic syndrome, body composition, socioeconomic data, demographic data, and dietary intake. After the comparison among the percentiles, chi-square was performed between P10 and P90 for dairy intake and demographic, clinic and dietetic variables. Logistic regression was used to identify the determinants of dairy intake in this population.

\section{Results}

Table 1 shows the characteristics of the study population in which $81.1 \%$ were female with low income (> 5 minimum wages), $68.8 \%$ with presence of abdominal obesity and $48.9 \%$ with diagnosis of obesity. Among the laboratory and clinical variables, lipids were the most altered component (HDL-c 40.2\% and TG 36.4\%) followed by high blood pressure (33.3\%) and hyperglycemia $(27.4 \%)$. Half of the subjects $(53.5 \%)$ presented up to two altered components of MetS, 3.1\% presented all five altered components and $11.4 \%$ had none of the altered components. MetS prevalence was found in $34.6 \%$ of subjects.

With regards the quality of the diet, only $3.5 \%$ of subjects had good diet quality according to healthy eating index (HEI higher than 100 points). Caloric contribution of macronutrients in a total daily energy intake of $1525 \pm 609 \mathrm{kcal}$ was $51.9 \%$ carbohydrates, $17.9 \%$ protein and $30.2 \%$ lipids. Dairy and calcium intake were below recommendation in $92.5 \%$ and $91.3 \%$ of individuals, respectively (Table 2 ).
Table 1: Characteristics of study population.

\begin{tabular}{|l|l|}
\hline \multicolumn{1}{|l|}{\begin{tabular}{l|} 
Gender \\
Women \\
Men
\end{tabular}} & $619(81.1)$ \\
\hline $\begin{array}{l}\text { Age, years } \\
<60\end{array}$ & $144(18.9)$ \\
$\geq 60$ & $530(65.9)$ \\
\hline $\begin{array}{l}\text { Income, wages } \\
<5\end{array}$ & $260(34.1)$ \\
$\geq 5$ & $574(75.2)$ \\
\hline $\begin{array}{l}\text { Education } \\
\text { Middle school } \\
\text { High school or college }\end{array}$ & $189(24.8)$ \\
\hline $\begin{array}{l}\text { Physical activity, minutes } \\
<150\end{array}$ & $314(41.1)$ \\
$\geq 150$ & $449(58.9)$ \\
\hline $\begin{array}{l}\text { Metabolic syndrome } \\
\text { Presence } \\
\text { Absence }\end{array}$ & $264(34.6)$ \\
\hline
\end{tabular}

Table 2: Diet quality and dairy and calcium intake $(n=763)$.

\begin{tabular}{|l|l|l|}
\hline Parameters & Mean \pm SD & \% Inadequacy \\
\hline Dairy (daily servings) & $1.3 \pm 1.2$ & 92.5 \\
\hline Calcium (mg/day) & $589 \pm 382$ & 91.3 \\
\hline HEI (points) & $76.4 \pm 14.8$ & 96.5 \\
\hline
\end{tabular}

HEI: Healthy Eating Index.

Dairy intake was not associated with gender, age and education in our cohort. The lower decile of dairy intake was associated with lower income, lower $\mathrm{HEI}$ lower intake of total energy, lower intake of saturated fatty acids, and lower intake of calcium (Table 3, Table 4 and Table 5). However, the lower dairy intake was not associated with the presence of MetS $(p=0.07)$ and rather, with hypertension $(p=0.001)$. The lower decile of dairy intake (zero serving) was associated with a $51 \%$ risk for hypertension, while the higher decile was associated with a lower risk (26\%) After adjustments, only calcium intake remained associated with the hypertension (Table 6).

The food intake markers of refined-processed diets (sodium/potassium, CHO/fibers, PUFA/MUFA and calcium/protein) showed no association with dairy intake distribution (data not shown).

\section{Discussion}

Among the individuals of our cohort, majority of females with low family income, poor diet, and abdominal obesity, lower dairy intake ( $>2.7$ serving vs. $<1$ serving) was associated with the presence of hypertension. Differently from other publications, lower dairy intake was distributed similarly between individuals with MetS and without MetS. It is noteworthy that the majority 
Table 3: Dairy consumption and socioeconomic and demographic variables.

\begin{tabular}{|c|c|c|c|c|c|c|c|}
\hline & $\begin{array}{l}\leq \mathbf{p} 10 \\
(0)\end{array}$ & $\begin{array}{l}\text { p10 - p25 } \\
(0.46)\end{array}$ & $\begin{array}{l}\text { p25 - p50 } \\
(1.02)\end{array}$ & $\begin{array}{l}\text { p50 - p75 } \\
(1.90)\end{array}$ & $\begin{array}{l}\text { p75 - p90 } \\
(2.70)\end{array}$ & $\begin{array}{l}\mathbf{p} \geq \mathbf{9 0} \\
(\geq 2.70)\end{array}$ & p-value \\
\hline \multicolumn{7}{|l|}{ Sex } & \multirow{3}{*}{0.09} \\
\hline Male & 26 & 9 & 32 & 31 & 19 & 19 & \\
\hline Female & 69 & 65 & 136 & 149 & 84 & 52 & \\
\hline \multicolumn{7}{|l|}{ Age, years } & \multirow{3}{*}{0.31} \\
\hline$\geq 60$ & 26 & 19 & 60 & 66 & 35 & 28 & \\
\hline$<60$ & 69 & 55 & 108 & 114 & 68 & 43 & \\
\hline \multicolumn{7}{|l|}{ Income, wages } & \multirow{3}{*}{0.01} \\
\hline$\leq 5$ & 85 & 62 & 128 & 134 & 74 & 51 & \\
\hline$>5$ & 10 & 12 & 40 & 45 & 29 & 20 & \\
\hline \multicolumn{7}{|l|}{ Education } & \multirow{3}{*}{0.11} \\
\hline Middle school & 45 & 35 & 68 & 71 & 50 & 21 & \\
\hline High school or college & 50 & 39 & 100 & 109 & 53 & 50 & \\
\hline
\end{tabular}

Table 4: Dairy consumption, body composition and metabolic syndrome.

\begin{tabular}{|c|c|c|c|c|c|c|c|}
\hline & $\begin{array}{l}\leq \mathbf{p} 10 \\
(0)\end{array}$ & $\begin{array}{l}\text { p10 - p25 } \\
(0.46)\end{array}$ & $\begin{array}{l}\text { p25 - p50 } \\
(1.02)\end{array}$ & $\begin{array}{l}\text { p50 - p75 } \\
(1.90)\end{array}$ & $\begin{array}{l}\text { p75 - p90 } \\
(2.70)\end{array}$ & $\begin{array}{l}p \geq 90 \\
(\geq 2.70)\end{array}$ & p-value \\
\hline \multicolumn{7}{|l|}{ BMI, $\mathbf{k g} / \mathrm{m}^{2}$} & \multirow{3}{*}{0.7} \\
\hline Normal & 46 & 41 & 89 & 84 & 53 & 34 & \\
\hline Obese & 48 & 33 & 78 & 94 & 49 & 37 & \\
\hline \multicolumn{7}{|l|}{ WC, cm } & \multirow{3}{*}{0.7} \\
\hline Normal & 22 & 23 & 49 & 54 & 30 & 25 & \\
\hline Elevated & 71 & 51 & 116 & 122 & 70 & 46 & \\
\hline \multicolumn{7}{|c|}{ Triglycerides, mg/dL } & \multirow{3}{*}{0.7} \\
\hline Normal & 50 & 44 & 81 & 94 & 55 & 31 & \\
\hline Elevated & 34 & 24 & 64 & 66 & 39 & 30 & \\
\hline \multicolumn{7}{|c|}{ Glycemia, mg/dL } & \multirow{3}{*}{0.7} \\
\hline Normal & 58 & 42 & 90 & 104 & 64 & 44 & \\
\hline Elevated & 26 & 25 & 49 & 45 & 30 & 15 & \\
\hline \multicolumn{7}{|c|}{ Blood Pressure } & \multirow{3}{*}{0.01} \\
\hline Normal & 39 & 24 & 65 & 85 & 46 & 42 & \\
\hline Elevated & 40 & 31 & 58 & 56 & 35 & 15 & \\
\hline \multicolumn{7}{|c|}{ HDL, $\mathrm{mg} / \mathrm{dL}$} & \multirow{3}{*}{0.30} \\
\hline Normal & 35 & 36 & 76 & 93 & 48 & 35 & \\
\hline Abnormal & 48 & 32 & 71 & 68 & 45 & 26 & \\
\hline \multicolumn{7}{|c|}{ Metabolic Syndrome } & \multirow{3}{*}{0.7} \\
\hline Presence & 35 & 30 & 65 & 58 & 36 & 24 & \\
\hline Absence & 60 & 43 & 103 & 120 & 66 & 46 & \\
\hline
\end{tabular}

BMI: Body Mass Index; kg: Quilos; m²: Square Meter; WC: Waist Circumference; cm: Centimeters; mg: Miligrams; dL: Deciliter; HDL: High Density Lipoprotein.

of the individuals had a low healthy eating index and therefore, a poor diet quality which is one the risk factors for elevated blood pressure and the development of hypertension [28]. Furthermore, lower dairy intake was associated with lower family income, lower intake of energy, lower saturated fatty acids intake and lower calcium intake. Calcium intake has important asso- ciations with essential blood hypertension [29]. Lee, et al. [18] showed in their meta-analysis that an increase of $200 \mathrm{~g} / \mathrm{d}$ of total dairy product intake was related to a lower risk of MetS components such as hyperglycemia, high blood pressure, hypertriglyceridemia and low HDL-cholesterol.

The present study showed that the great majority of 
Table 5: Dairy consumption and nutrient intake.

\begin{tabular}{|l|l|l|l|l|l|l|l|}
\hline & $\mathbf{5}$ 10 & $\mathbf{p 1 0}-\mathbf{p 2 5}$ & $\mathbf{p 2 5}-\mathbf{p 5 0}$ & $\mathbf{p 5 0}-\mathbf{p 7 5}$ & $\mathbf{p 7 5}-\mathbf{p 9 0}$ & $\mathbf{p} \geq \mathbf{9 0}$ \\
$(0)$ & $(0.46)$ & $(1.02)$ & $(1.90)$ & $(2.70)$ & $\mathbf{p}$-value \\
\hline $\mathrm{HEI}$ & $70.7 \pm 15.2$ & $71.9 \pm 14.5$ & $76.8 \pm 14.1$ & $78.3 \pm 13.5$ & $80.8 \pm 13.7$ & $77.4 \pm 17.2$ & $\mathbf{0 . 0 0 1}$ \\
\hline Energy, calories & $1365.8 \pm 610.9$ & $1355.5 \pm 651.8$ & $1470.1 \pm 584.3$ & $1568.4 \pm 640.2$ & $1668.3 \pm 553.9$ & $1750.8 \pm 528.7$ & $\mathbf{0 . 0 0 0 1}$ \\
\hline Carbohydrate, \% & $52.5 \pm 11.3$ & $53.6 \pm 10.8$ & $52.0 \pm 10.5$ & $52.7 \pm 8.6$ & $50.21 \pm 9.1$ & $49.5 \pm 8.9$ & 0.07 \\
\hline Protein, \% & $17.1 \pm 7.7$ & $17.5 \pm 6.4$ & $18.1 \pm 5.8$ & $17.7 \pm 4.9$ & $18.0 \pm 5.1$ & $18.7 \pm 4.4$ & 0.51 \\
\hline Total fat, \% & $30.6 \pm 9.0$ & $29.3 \pm 9.6$ & $29.6 \pm 8.4$ & $29.5 \pm 7.2$ & $31.6 \pm 7.7$ & $31.2 \pm 7.4$ & 0.21 \\
\hline SFA, \% & $7.1 \pm 3.6$ & $8.2 \pm 3.8$ & $8.4 \pm 3.6$ & $9.3 \pm 3.6$ & $10.2 \pm 3.6$ & $10.9 \pm 4.3$ & $\mathbf{0 . 0 0 0 1}$ \\
\hline Calcium, mg & $221.8 \pm 131.8$ & $311.2 \pm 154.9$ & $457.7 \pm 231.1$ & $635.9 \pm 193.5$ & $826.9 \pm 241.7$ & $1263.2 \pm 486.5$ & $\mathbf{0 . 0 0 0 1}$ \\
\hline $\begin{array}{l}\text { Sodium/potassium, } \\
\text { mg }\end{array}$ & $0.6 \pm 0.7$ & $0.8 \pm 0.7$ & $0.6 \pm 0.4$ & $0.6 \pm 0.5$ & $0.7 \pm 0.5$ & $0.6 \pm 0.4$ & 0.7 \\
\hline
\end{tabular}

HEI: Healthy Eating Index; SFA: Saturated Fatty Acids.

Table 6: Logistic regression for low dairy intake.

\begin{tabular}{|l|l|l|l|}
\hline & Odds Ratio & Cl (95\%) & p-value \\
\hline Intercept & & & \\
\hline Calcium, mg & 0.98 & $0.96-0.99$ & 0.004 \\
\hline Gender (M/F) & 1.38 & $0.07-27.5$ & 0.83 \\
\hline Age, years & 0.05 & $<0.001-12.7$ & 0.30 \\
\hline BMI, kg/m ${ }^{2}$ & 0.96 & $0.77-1.20$ & 0.73 \\
\hline Energy intake, calores & 1.00 & $0.99-1.00$ & 0.29 \\
\hline
\end{tabular}

BMI: Body Mass Index; kg: Kilos; m²: Square Meter; Cl: Confidence Interval.

the individual presented poor diet quality which is characterized by low amounts of fruit and vegetables and whole grains. This dietary habit may be associated with the prevalence of hypertension and MetS in this population. The mediterranean diet (MD) is so far the most well studied dietary pattern and are related to prevention of disease risk factors, such as hypertension, dyslipidemia, and obesity [8]. Individuals with high systolic and/or diastolic blood pressures can have beneficial effects with adherence to MD according to clinical trials $[30,31]$. In addition, the original Dietary Approaches to Stop Hypertension (DASH) trial demonstrated that a diet that emphasizes fruits, vegetables, and low-fat dairy products, that includes whole grains, poultry, fish, and nuts, that contains only small amounts of red meat, sweets, and sugar-containing beverages, and that contains decreased amounts of total and saturated fat and cholesterol lowers blood pressure substantially both in people with hypertension and those without hypertension, as compared with a typical diet in the United States [32].

Burini, et al. [8] showed that MetS was more common in less-educated and low-income subjects, presenting lower physical activity and eating obesogenic-atherogenic diets characterized by low intake of fruit, dietary fiber, vegetables and whole grains, along with high intake of carbohydrates, sugar, refined grains and processed food, fat, cholesterol and soybean oil. However, considering the overall poor quality of subjects diet, food intake was more related to the individual
MetS-altered components rather than with MetS prevalence itself [8]. On the other hand, an adequate intake of fruits and a traditional pattern consisted of non-starchy vegetables, fresh fruit juice, whole wheat bread, dairy and fish represented protective factors against some of the components of metabolic syndrome [33,34]. Overall, an adequate intake of fruit and the intake of more than 8 different items in the diet (variety) showed to be a protective factor against MetS diagnosis, while saturated fat intake higher than $10 \%$ of total caloric intake represented a high risk for developing MetS [11].

The nutritional requirements of contemporary humans were almost certainly established over evolutionary experience. The best available evidence indicates that this evolution occurred in a high-calcium nutritional environment. Interesting, Paleolithic nutrition has been criticized as being too low in calcium intake [35]. As shown in a RCT study involving a Paleolithic diet group, calcium intake was indeed lower but, the lower calcium intake was compensated for by lower calcium excretion, which led the authors to speculate that "calcium homeostasis was unlikely to have become compromised" [36]. In fact, one of the non-controlled Paleolithic dietary intervention studies also showed a decrease from baseline in calcium excretion after 10 day consumption of the Paleolithic diet [37]. Additionally, the low-salt, high-protein, and alkalizing properties of Paleo nutrition may substantially contribute to a healthy calcium balance [37-40]. The typical Western diet yields a net acid load estimated to be $50 \mathrm{mEq} / \mathrm{d}$. As a result, healthy adults consuming the standard US diet sustain a chronic, low-grade pathogenic metabolic acidosis that worsens with age as kidney function declines [5].

The present study fail to show association of dairy intake with markers of refined-processed diets such as sodium-to-potassium ratio which represents an imbalance in the diet. In our previous data, higher blood pressure was associated with a dietary characteristics of high "processed pattern" (high sodium, low potassium and calcium, high sugar, low fiber) [41]. Moreover, a 
dietary variety with $\geq 8$ food items showed a protective effect for alterations in systolic blood pressure and, the quality of the ingested diet was negatively associated with diastolic blood pressure [42].

Lower dairy intake was also distributed similarly between obese and non-obese individuals. However, in a previous sample of this cohort it was shown that an increase in dairy intake was the main dietary factor associated with reductions in body weight in overweight adults after 20 weeks of lifestyle change program [35]. The role of dairy intake for weight loss is still not elucidated. Some studies have looked into calcium (91.3\% of inadequacy, in the present sample), others into protein, but perhaps both work synergistically [4,5,43-45]. The protein portion of the milk contains casein (80\%), which is absorbed slowly and delays gastric emptying, and whey protein (20\%), which is absorbed quickly and is rich in branched-chain amino acids that activate some satiety hormones, namely glucagon-like peptide-1 (GLP1) and peptide YY (PYY) $[28,46]$.

The present study has some limitations: 1) A convenience sample was used for this study which does not allow generalizations for the Brazilian population; 2) The dietary intake was evaluated by a analysis of 24hour recall and this fact represents the principal limitation of the study since one 24-hour recall does not detect dietary intake variability.

In conclusion, this study found an inverse association of dairy intake and presence of hypertension, which may support the potential benefit of dairy consumption, as part of a balanced diet and a healthy lifestyle, to prevent the development or delay the onset hypertension in this population.

\section{References}

1. O'Keefe JH, Vogel R, Lavie CJ, Cordain L (2011) Exercise like a hunter-gatherer: A prescription for organic physical fitness. Prog Cardiovasc Dis 53: 471-479.

2. Cordain L, Miller JB, Eaton SB, Mann N, Holt SH, et al. (2000) Plant animal subsistence ratios and macronutrient energy estimations in worldwide hunter-gatherer diets. Am J Clin Nutr 71: 682-692.

3. Burini RC, Nunes CNM, Kano HTK, Nakagaki MS (2016) Epygenetics of plasma cholesterol variation: From the mismatched evolutionary genome with the current obesogenic environment to the lifestyle modification as a primary care of free-living adults in a Brazilian community. In: Jody Morton, Metabolic syndrome: Clinical aspects, management options and health effects. Nova Science Publ.

4. Manheimer EW, Van Zuuren EJ, Fedorowicz Z, Pijl H (2015) Paleolithic nutrition for metabolic syndrome: Systematic review and meta-analysis. Am J Clin Nutr 102: 922-932.

5. Cordain L, Eaton SB, Sebastian A, Mann N, Lindeberg S, et al. (2005) Origins and evolution of the Western diet: Health implications for the 21st century. Am J Clin Nutr 81: 341354.

6. Peterlik M, Cross HS (2005) Vitamin D and calcium deficits predispose for multiple chronic disease. Eur J Clin Invest 5: 290-304.

7. McLellan KCP, Ramos FMM, Corrente JE, Sloan LA, Burini RC (2015) Evolutionary roles of dietary fiber in succeeding metabolic syndrome (MetS) and its responses to a lifestyle modification program: A Brazilian Community-based study. In: Marvin E Clemens, Dietary fiber: Production challenges, food sources and health benefits. Nova Publishers 978: 6365.

8. Burini RC, Kano HTK, Burini FHP, McLellan KCP (2016) Metabolic syndrome - From the mismatched evolutionary genome with the current obesogenic environment to the lifestyle modification as a primary care of free-living adults in a Brazilian community. In: Jody Morton, Metabolic Syndrome: Clinical aspects, management options and health effects. Nova Science Publ.

9. Ricci I, Artacho R, Olalla M (2010) Milk protein peptides with angiotensin l-converting enzyme inhibitory (ACEI) activity. Crit Rev Food Sci Nutr 50: 390-402.

10. Astrup A (2014) Yogurt and dairy product consumption to prevent cardiometabolic diseases: Epidemiologic and experimental studies. Am J Clin Nutr 99: 1235S-1242S.

11. Lamarche B (2008) Review of the effect of dairy products on non-lipid risk factors for cardiovascular disease. J Am Coll Nutr 27: 741S-746S.

12. Dugan CE, Fernandez ML (2014) Effects of dairy on metabolic syndrome parameters: A review. Yale J Biol Med 87: 135-147.

13. Chen M, Pan A, Malik VS, Hu FB (2012) Effects of dairy intake on body weight and fat: $A$ meta-analysis of randomized controlled trials. Am J Clin Nutr 96: 735-747.

14. Azadbakht L, Mirmiran P, Esmaillzadeh A, Azizi F (2005) Dairy consumption is inversely associated with the prevalence of the metabolic syndrome in Tehranian adults. Am J Clin Nutr 82: 523-530.

15. Shin H, Yoon YS, Lee Y, Kim C, Oh SW (2013) Dairy product intake is inversely associated with metabolic syndrome in Korean adults: Anseong and Ansan cohort of the Korean Genome and Epidemiology Study. J Korean Med Sci 28: 1482-1488.

16. Martins ML, Kac G, Silva RA, Bettiol H, Barbieri MA, et al. (2015) Dairy consumption is associated with a lower prevalence of metabolic syndrome among young adults from Ribeirao Preto, Brazil. Nutrition 31: 716-721.

17. Louie JC, Flood VM, Rangan AM, Burlutsky G, Gill TP, et al. (2013) Higher regular fat dairy consumption is associated with lower incidence of metabolic syndrome but not type 2 diabetes. Nutr Metab Cardiovasc Dis 23: 816-821.

18. Lee M, Lee H, Kim J (2018) Dairy food consumption is associated with a lower risk of the metabolic syndrome and its components: A systematic review and meta-analysis. $\mathrm{Br}$ J Nutr 120: 373-384.

19. Mclellan KCP, Pimentel GD, Corrente JE, Burini RC (2010) Association of fat intake and socioeconomic status on anthropometric measure of adults. Cadernos Saúde Coletiva (UFRJ) 18: 266-274.

20. Lohman TG, Roche AF, Martorell R (1988) Anthropometric standardization reference manual. Human Kinetcs: Champaign.

21. World health organization (1995) Physical status: The use and interpretation of anthropometry. WHO Technical Report Series 452. 
22. Lipschitz DA (1994) Screening for nutritional status in the elderly. Primary Care 21: 55-67.

23. Expert Panel on Detection, Evaluation and Treatment of High Blood Cholesterol in Adults (2001) Executive summary of the third report of the National Cholesterol Education Program (NCEP) expert panel on detection, evaluation, and treatment of high blood cholesterol in adults (Adult Treatment Panel III). JAMA 285: 2486-2497.

24. Grundy SM, Brewer HB Jr, Cleeman JI, Smith SC Jr, Lenfant C, et al. (2004) Definition of metabolic syndrome: Report of the National Heart, Lung, and Blood Institute/American Heart Association conference on scientific issues related to definition. Arterioscler Thromb Vasc Biol 24: e13-e18.

25. Kennedy ET, Ohls J, Carlson S, Fleming K (1995) The Healthy Eating Index: Design and applications. J Am Diet Assoc 95: 1103-1108.

26. Fisberg RM (2005) Recomendações nutricionais. In: Fisberg RM, Slater B, Marchioni DML, Martini LA, Inquéritos alimentares: Métodos e bases científicos. Manole, 190-236.

27. Ministério da Saúde, Secretaria de Atenção à Saúde, Departamento de Atenção Básica (2014) Guia Alimentar para a População Brasileira. ( ${ }^{\text {nd }}$ edn), Brasília (DF).

28. Chobanian AV, Bakris GL, Black HR, Cushman WC, Green LA, et al. (2003) Seventh report of the Joint National Committee on prevention, detection, evaluation, and treatment of high blood pressure. Hypertension 42: 12061252.

29. Waib PH, Papini-Berto SJ, Habermann F, Burini RC (1992) Calcium-intake assessment in essential-arterial hypertensive patients. Revista de Saúde Pública 26: 27-33.

30. Estruch R, Martinez-Gonzalez MA, Corella D, Salas Salvado J, Ruiz-Gutierrez V, et al. (2006) Effects of a Mediterranean-style diet on cardiovascular risk factors: A randomized trial. Ann Intern Med 145: 1-11.

31. Rallidis LS, Lekakis J, Kolomvotsou A, Zampelas A, Vamvakou G, et al. (2009) Close adherence to a Mediterranean diet improves endothelial function in subjects with abdominal obesity. Am J Clin Nutr 2: 263-268.

32. Appel LJ, Moore TJ, Obarzanek E, Vollmer WM, Svetkey LP, et al. (1997) A clinical trial of the effects of dietary patterns on blood pressure. DASH collaborative research group. N Engl J Med 336: 1117-1124.

33. Marsola FC, Rinaldi AEM, Siqueira M, McLellan KCP, Corrente JE, et al. (2011) Association of dietary patterns with metabolic syndrome components in low-income, freeliving Brazilian adults. International Journal of Nutrition and Metabolism 3: 31-38.

34. Oliveira ÉP, Camargo KF, Castanho GKF, Nicola M, McLellan KCP, et al. (2012) A variedade da dieta é fator protetor para a pressão arterial sistólica elevada. Arq Bras Cardiol 98: 1-6.

35. Eaton SB, Nelson DA (1991) Calcium in evolutionary perspective. Am J Clin Nutr 54: 281S-287S.

36. Boers I, Muskiet FA, Berkelaar E, Schut E, Penders R, et al. (2014) Favourable effects of consuming a Palaeolithictype diet on characteristics of the metabolic syndrome: A randomized controlled pilot-study. Lipids Health Dis 13: 160.

37. Frassetto LA, Schloetter $M$, Mietus-Synder M, Morris RC Jr, Sebastian A (2009) Metabolic and physiologic improvements from consuming a paleolithic, huntergatherer type diet. Eur J Clin Nutr 63: 947-955.

38. Sebastian A, Frassetto LA, Sellmeyer DE, Merriam RL, Morris RC Jr (2002) Estimation of the net acid load of the diet of ancestral preagricultural Homo sapiens and their hominid ancestors. Am J Clin Nutr 76: 1308-1316.

39. Teucher B, Dainty JR, Spinks CA, Majsak-Newman G, Berry DJ, et al. (2008) Sodium and bone health: Impact of moderately high and low salt intakes on calcium metabolism in postmenopausal women. J Bone Miner Res 23: 14771485.

40. Remer T, Krupp D, Shi L (2014) Dietary protein's and dietary acid load's influence on bone health. Crit Rev Food Sci Nutr 54: 1140-1150.

41. Burini RC, Kano HT, Nakagaki MS, das Neves Mendes Nunes C, Burini FHP (2017) The lifestyle modification effectiveness in reducing hypertension in a Brazilian Community: From the epigenetic basis of ancestral survival to the contemporary lifestyle and public health initiatives. Heighpubs J Clin Hypertens 1: 10-31.

42. Takahashi MM, de Oliveira EP, de Carvalho AL, de Souza Dantas LA, Burini FH, et al. (2011) Metabolic syndrome and dietary components are associated with coronary artery disease risk score in free-living adults: A cross-sectional study. Diabetol Metab Syndr 3: 7.

43. Frassetto L, Morris RC Jr, Sellmeyer DE, Todd K, Sebastian A (2001) Diet, evolution and aging-the pathophysiologic effects of the post-agricultural inversion of the potassiumto-sodium and base-to-chloride ratios in the human diet. Eur J Nutr 40: 200-213.

44. Cordain $L$ (2002) The nutritional characteristics of a contemporary diet based upon Paleolithic food groups. JAMA 5: $15-24$.

45. DiBello JR, McGarvey ST, Kraft P, Goldberg R, Campos H, et al. (2009) Dietary patterns are associated with metabolic syndrome in adult Samoans. J Nutr 139: 1933-1943.

46. O'Dea K (1991) Westernisation, insulin resistance and diabetes in Australian aborigines. Med J Aust 155: 258-264. 